\title{
The Governmental Environmental Investment Project Performance Audit Index System Research
}

\author{
Jinyu Tian $^{1, a}$ and Ziyuan Zhang ${ }^{2, b}$ \\ ${ }^{1}$ North China Electric Power University, Baoding, Hebei 071003, China \\ ${ }^{2}$ North China Electric Power University, Baoding, Hebei 071003, China \\ a769774965@qq.com, bhuadianzhangzy@163.com
}

Keywords: governmental environmental investment project; performance auditing; index system; the balanced scorecard.

\begin{abstract}
The governmental environmental investment project performance audit as a new topic in the field of auditing is shouldering the environmental performance audit supervision function under the new situation. But the lack of performance index system becomes a main reason of the obstacle to the department of the environmental performance auditing in our country. The paper firstly introduces the basic theory of governmental environmental investment project performance audit. Secondly, it analyzes the rationality of using the balanced scorecard concept to build the performance audit index system. Finally, combining with the analysis and study of the characteristics of governmental environmental investment projects which has public interest attribute, the paper draws lessons from the balanced scorecard concept and builds a set of governmental environmental investment project performance audit index system.
\end{abstract}

\section{Introduction}

In recent years, China's macroeconomic situation continues to maintaining steady development, urbanization construction speed is still fast, but environmental pollution problem which lets people feel terrible has cropped up. Over the years, while increasing our efforts to solve environmental problems, which achieved some success, due to the industrial structure and layout which are not quite reasonable, environmental supervision system is not perfect, the level of economic development and many other factors' limit, the situation of environment protection is still very grim.

Throughout the development course of the world audit theory and practice, performance audit has become one of the main directions of the audit development. The development of China governmental audit is also required to meet the trend of audit development in the world ${ }^{[1]}$. One important and difficult point of the performance audit is how to design the index system of performance audit ${ }^{[2]}$. The paper will research the governmental environmental investment project performance audit index system, and hope to establish a scientific and useful environmental investment project performance audit index system.

\section{Basic theory of the governmental environmental investment project performance audit}

\subsection{Overview of environmental investment project performance audit.}

We consider that governmental environmental investment project refers that in order to maintain and restore the ecological environment quality and manage environmental pollution, the government mainly organizes and implies construction projects through the budget funding, financing in the form of treasury bonds or local government bonds and bank loans of state financial guarantees and so on, which after the completion of provide basic form of environmental public goods and services to the masses, mostly operating and managing by non-profit organizations. Such as towns river regulation, urban sewage treatment, garbage consumptive, air pollution control, noise source control, returning farmland forest and ecological conservation projects, belong to environmental investment projects.

Since the environment product is a typical public goods product, governmental environmental investment project can be divided into pollution control project, capacity construction project and 
operation guarantee project by different project core performance objectives ${ }^{[3]}$. The core performance objective of pollution control project is pollution control of key pollution sources, the core performance objective of capacity construction project is that to improve the ecological environment and increase the self-healing capacity of the natural environment, the core performance objective of operation guarantee project is to enhance environmental monitoring capacity and other supporting guarantee capabilities required in daily operations.

2.2 Contents of the governmental environmental investment project performance audit.

After summarizing existing research results and view of all parties, we consider that main contents of the governmental environmental investment project performance audit include the following areas:

(1) Audit performance situation of environmental fund management, use, investment control and efficient operation of the economy;

(2) Audit performance of relevant policies' measures enforcement and performance which meets the health needs of the masses;

(3) Audit performance of the case project management and operations management;

(4) Audit performance of the work which plays sustainable project environmental effects done by project main part.

\section{Environmental investment project performance audit index system construction}

Currently, common and traditional performance audit index systems are more influenced by consideration of the enterprise performance evaluation when developed and designed, which emphasizes on the operating results and short-term benefits assessment, so there are problems that economic indicators weight is too high, the economic globalization tendency is obvious, the attention to the environmental protection and efficiency and rational utilization of resource is not enough, a lack of intangible assets evaluation and human capital cost changes indicators, and the qualitative evaluation of management strategy, innovation and development and social contribution lacks conversion process to quantitative evaluation.

The Balanced Scorecard emphasizes the balance and unity philosophy, committing to the implementation of the established organizational strategy, regulation of the organization action, attaches great importance to mining and developing organization internal sustainable development potentiality, and advocates individual action plan co-ordinate to the strategic direction of the organization. To design the performance audit index system by the direction provided by balanced scorecard comprehensively considers the performance forms of governmental environmental investment project, which will help to deeply analyze the improvement of project performance internal driving force source.

\section{The governmental environmental investment project performance audit index system construction}

Environmental investment project performance audit index system is embodiment of performance audit standards and performance audit key content, which lets performance standards required by governmental environmental investment project perform concretely quantitative or qualitative forms ${ }^{[4]}$. We learn from the Balanced Scorecard theory, set the audit evaluation governmental environmental investment project performance as the overall strategy objectives, then set the financial benefits, public feedback, internal management, learning and development these four sides as the one-lever index of performance audit evaluation, and design specifically second-lever index in four large dimensions based on the salient features of governmental environmental investment project. 
Table 1 Governmental environmental investment project performance audit index system

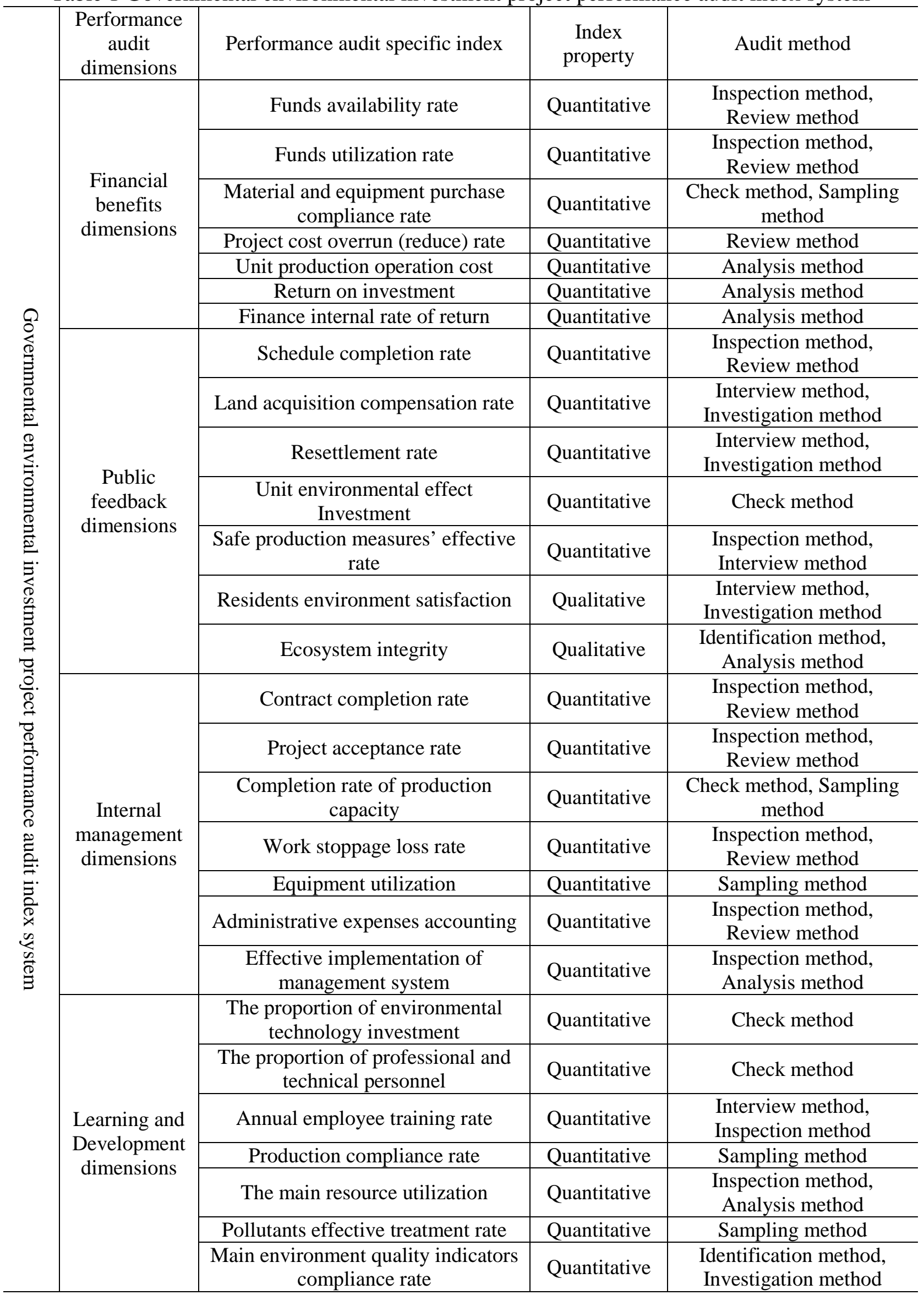

It should be noted that due to a wide range of the governmental environmental investment projects, and the focus and the evaluation scopes of different categories of governmental 
environmental investment projects performance audit are different, it cannot mechanically set index system constructed in the paper for all governmental environmental investment project performance audit. In practice, it should be appropriate to add or delete the relevant indicators by specific types and properties scopes of governmental environmental investment projects ${ }^{[5]}$.

Governmental environmental investment projects mainly provide public environment goods, its pricing and sales strategy is mainly guided or imposed to imply by the government, which means that the price of public environment goods is stable, unlike manufactured goods price fluctuating frequently because of supply and demand, for those governmental environmental investment projects which can achieve break-even in the operating, such as the environmental investment project BOT (build-operate-transfer) operation mode, whose profit model is different of general manufacturing enterprises' ${ }^{[6]}$. Government often determines the price of environment goods through the approach of "cost + reasonable return". Therefore, financial benefit dimension indicators are not traditional indicators, whose meaning and extension is all expanded.

Public feedback dimension index is designed to reflect the public real personal experience or potential benefit due to the implementation of governmental environmental investment project, so screening index system seeks to cover key factors which impact personal well-being of the masses.

Internal management dimension index is designed to consider implementation of environmental investment project on the construction program standards, internal control system construction and implementation, sound degree of self-restraint system and other aspects. What internal management dimension index measures is that achieving the internal driving force of environmental investment projects efficient and stable operation, which but also affects the important aspects of the project environmental performance improvement. Through the project management activities performance audit, we can search precisely effective increasing point of management performance, propose optimization proposal and carry out timely and effective information feedback, which will improve the project overall performance level.

Learning and development dimension index is designed to reflect environmental investment project's effort and enthusiasm about sustainability in pollution control capability, which is mainly reflected on the popularization of environment protection theory and knowledge, the development of sustainable thinking, progress of environment protection research, and the training of the rational use of public resources and etc..

\section{Conclusion}

The governmental environmental investment project performance audit index system building in the paper, which uses the core concept of the Balanced Scorecard, redesigns financial benefits, public feedback, internal management, learning and development these four dimensions performance audit indicators, expanses horizontally performance audit evaluation standards' connotation breadth at the theoretical aspect, and screens performance audit indicators again from the view of a complete process covering project construction and operation, which expanses longitudinally performance audit evaluation standards' connotation depth at the application aspect.

As an advanced performance regulation method, governmental environmental investment project performance audit plays an increasingly important role in enhancing the efficiency of environment protection resource allocation, improving public financial expenditure structure, and strengthening government authority supervision and restriction. It becomes cutting-edge technology and the latest development in the performance audit field, which should attract performance audit areas experts, scholars and audit practitioners' more attention.

\section{References}

[1]. Wang Yanping, “International Comparative Study on Government Performance Audit Standards,” Audit Monthly, 2008, 06:9-11. (In Chinese) 
[2]. Lu Qiuting, “The public policy audit theory, plans and methods study based on international comparisons,” Business Accounting, 2014, 13:62-65. (In Chinese)

[3]. Connier, Denis, Gordon, and Irene, “An examination of social environmental reporting strategies,” Accounting, Auditing \& Accountability Journal, 2001.5.

[4]. Li Dandan, “Study simply how to carry out construction project performance audit," Modern Economic Information, 2014, 12:182. (In Chinese)

[5]. Li Xiaodong, "Government investment performance audit issues and strategies to deal with,” Modern Economic Information, 2014, 12:183-184. (In Chinese)

[6]. He Yuanyuan, "Application of Fuzzy Comprehensive Evaluation Method in Governmental Public Projects Performance Audit Evaluation,” Modern Business, 2014, 18:128-129. (In Chinese) 